REVISTA DE GESTAOO ESECRETARIADO

MANAGEMENT AND ADMINISTRATIVE

PROFESSIONAL REVIEW
Organização: SINSESP

Editora Científica: Dra. Rosimeri Ferraz Sabino Avaliação: Double Blind Review pelo SEER/OJS

Revisão: Gramatical, normativa e de formatação

Data de recebimento do artigo: $30-10-2017$

Data de aceite do artigo: $14-08-2018$

\title{
Produção monográfica: significados e dificuldades na visão dos estudantes
}

\author{
Daniela Giareta Durante \\ Doutoranda em Administração e Controladoria na Universidade Federal do Ceará (UFC). \\ Professora efetiva do curso de Secretariado Executivo da UFC. \\ E-mail: danielagiareta@gmail.com (Brasil)
}

Janaina Lima de Souza Ribeiro

Bacharela em Secretariado Executivo pela Universidade Federal do Ceará (UFC).

E-mail: janainalsouza@hotmail.com (Brasil)

\section{Thays Lyanny da Cunha Garcia da Rocha}

Bacharela em Secretariado Executivo pela Universidade Federal do Ceará (UFC).

E-mail: thayslyanny@hotmail.com (Brasil)

\section{Resumo}

A produção monográfica é um meio de inserir o aluno da graduação na pesquisa científica, tornando-o responsável por gerar conhecimento e ser sujeito ativo no seu processo de formação (Severino, 2007; Demo, 2011). A problemática desta pesquisa consiste no seguinte questionamento: que significados são atribuídos pelos estudantes à elaboração da monografia? Esta investigação justifica-se pela inexistência de pesquisas que tratem das percepções dos alunos de Secretariado Executivo sobre o tema, sendo relevante conhecer tais percepções, uma vez que a monografia não é um componente obrigatório para a conclusão da graduação na área, e estudos que evidenciem tais percepções podem contribuir para maior interesse dos estudantes de graduação na pesquisa científica. O objetivo geral consiste em compreender o significado da produção monográfica para os egressos do curso de bacharelado em Secretariado Executivo da Universidade Federal do Ceará [UFC]. No que se refere aos aspectos metodológicos, trata-se de uma pesquisa qualitativa e descritiva. A técnica de coleta de dados empregada foi questionário, e a análise foi realizada por meio da análise de conteúdo. A abordagem teórica contempla estudos da Educação que discutem a formação acadêmica e os estudos sobre pesquisa em Secretariado. Os sujeitos apontaram dificuldades de ordem pessoal e institucional, mas estas parecem não comprometer a produção monográfica. Concluiu-se que o trabalho monográfico impacta positivamente na satisfação dos estudantes, contribuindo tanto para o seu desenvolvimento intelectual quanto pessoal. Ademais, esses trabalhos fomentam e enriquecessem as pesquisas na área secretarial.

Palavras-chave: Pesquisa. Formação acadêmica. Monografia. 


\title{
Monographic production: meanings and difficulties in the vision of students
}

\begin{abstract}
Monographic production is a way to insert undergraduate students in scientific research study, making them responsible for producing knowledge, besides being an active subject in their own academic formation (Severino, 2007; Demo, 2011). The research study question is: which meanings do students assign to the elaboration of the monograph? This research study is justified by the inexistence of researches on students' Executive Secretariat perceptions about this subject, in addition, it is relevant to recognize such perceptions, because the monograph is not a mandatory component for graduation in the area and because studies that evidence such perceptions can contribute to the interest of undergraduate students in scientific research. The general objective is to understand the meaning of monograph writing for the Secretarial Science undergraduate students of the Universidade Federal do Ceará [UFC]. The research is qualitative and descriptive. The technique for data collection was a questionnaire and the results were analyzed through content analysis. The theoretical approach contemplates studies of Education that discuss academic formation and studies concerning research on Secretarial Science. It was concluded that the monographic work is positive and satisfactory for students, which contributes to intellectual and personal development, as well as it is a reason for achievement and enrichment for the area. The students also pointed to personal and institutional difficulties, but these ones do not compromise the monographic production.
\end{abstract}

Keywords: Research. Academic education. Monograph.

\section{Como referenciar em APA:}

Durante, D. G., Ribeiro, J. L. de S., \& Rocha, T. L. da C. G. (2019). Produção monográfica: significados e dificuldades na visão dos estudantes. R.G.Secr., GESEC, 10(1), 26-46.

\section{Como referenciar em ABNT:}

DURANTE, D. G.; RIBEIRO, J. L. S.; ROCHA, T. L. C. G. Produção monográfica: significados e dificuldades na visão dos estudantes. R.G.Secr.,GESEC, São Paulo, v. 10, n. 1, p. 26-46, jan.-abr. 2019.
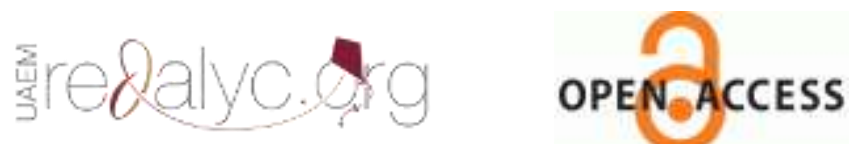


\section{Introdução}

A importância da pesquisa e da produção científica durante a graduação é um tema debatido e defendido por estudiosos de diferentes áreas do conhecimento, por contribuir de forma significativa na formação crítica do aluno, desenvolver habilidade de questionamento, identificação de problemas, além de ser uma oportunidade de teorizar a prática profissional (Severino, 2007). Demo (2011, p. 78) assegura que "sem pesquisa, não há vida acadêmica, a menos que a reduzamos a uma tática incolor de repasse copiado".

Têm-se no ensino superior, sobretudo no âmbito das universidades e cursos de bacharelados e licenciaturas, a missão da indissociabilidade entre ensino, pesquisa e extensão. Severino (2007, p. 24) explica a relação entre os três eixos, sendo a pesquisa responsável por fomentar o ensino e a extensão de forma que "só se aprende, só se ensina, pesquisando; só se presta serviço à comunidade, se tais serviços nascerem e se nutrirem da pesquisa".

Portanto, a realização do trabalho monográfico é considerada um dos meios para incluir o aluno no mundo da pesquisa durante a graduação. Oliveira e Durante (2016) reafirmam que a monografia é uma maneira de introduzir o aluno de Secretariado Executivo no universo da pesquisa científica e se faz importante para o fortalecimento da formação acadêmica, além do fortalecimento da profissão secretarial.

As Diretrizes Curriculares Nacionais [DCN] para os cursos de bacharelado em Secretariado Executivo determinam os conteúdos que, obrigatoriamente, devem fazer parte da integralização curricular e deixam aberta a possibilidade de o curso incluir outros conteúdos para atender características regionais. O Trabalho de Conclusão de Curso [TCC] não é componente obrigatório pelas DCN, ficando a cargo de cada Instituição de Ensino Superior [IES] a escolha de contemplar ou não na integralização curricular (Brasil, 2005). Quando adotado o TCC, este pode ser "desenvolvido nas modalidades de monografia, projeto de iniciação científica ou projetos de atividades centrados em áreas teórico-práticas e de formação profissional relacionadas com o curso" (Brasil, 2005, p. 4).

O fato de o trabalho monográfico não ser obrigatório na integralização curricular demonstra que a pesquisa científica não é tratada como prioridade na graduação em Secretariado Executivo e sinaliza a falta de uma cultura voltada para a pesquisa, como já apontada por Cantarotti (2016), Durante (2012), Maçaneiro (2012) e Piccoli, Gonçalves, Soares e Martins (2016), entre outros. A deficiência em pesquisa científica levou o secretariado a 
passar por uma consulta pública do Ministério da Educação [MEC], em 2009, sob questionamento da continuidade do curso de bacharelado em Secretariado devido a pouca contribuição científica na área (Martins, Maccari, Silva e Todorov, 2014; ABPSEC, 2016). Desde então, observa-se uma movimentação na área em prol da pesquisa científica, com o aumento e qualificação da produção científica, criação de periódicos e eventos acadêmicos, criação de grupos de pesquisa e criação de uma associação de pesquisadores, a Associação Brasileira de Pesquisa em Secretariado [ABPSEC] (Durante \& Pereira, 2016).

No curso de bacharelado em Secretariado Executivo da Universidade Federal do Ceará [UFC], em funcionamento desde 1995, a monografia é um componente obrigatório para a conclusão do curso. Os estudantes, no último semestre do curso, podendo iniciar antes, mediante matrícula, realizam a atividade de monografia sob a orientação de um professor, e ao final do semestre, submetem à apreciação de uma banca examinadora. Essa experiência possibilita ao estudante iniciação à pesquisa durante a graduação, gerando benefícios a eles, à formação, ao curso e à profissão, como apontado por Demo (2011) e Severino (2007). Por outro lado, nem sempre os alunos percebem esses benefícios (Durante \& Santos, 2012).

Diante disso, surgiu o questionamento que deflagrou a presente pesquisa: Que significados são atribuídos pelos estudantes à elaboração da monografia? Assim, o objetivo central do estudo é compreender o significado da produção monográfica para os egressos do curso bacharel em Secretariado Executivo da Universidade Federal do Ceará. Como objetivos específicos, definiram-se: a) identificar os estudantes que defenderam suas monografias no período de 2013.2 a 2016.1; b) entender o significado atribuído pelos estudantes ao trabalho monográfico; c) levantar as dificuldades encontradas pelos estudantes na elaboração da monografia; d) levantar soluções para as dificuldades, na visão dos estudantes.

Essa investigação se justifica pela inexistência de pesquisas no Secretariado Executivo que tratem das percepções dos alunos sobre a produção monográfica e é importante conhecer tais percepções justamente porque a monografia não é obrigatória para a integralização curricular, conforme as DCN (Brasil, 2005), mas é um componente adotado por vários cursos de Secretariado Executivo no Brasil em razão dos benefícios trazidos para a formação do estudante (Oliveira \& Durante, 2016). Outra justificativa é que a área de secretariado busca o fortalecimento da pesquisa científica e estudos dessa natureza podem contribuir para maior interesse dos estudantes de graduação na pesquisa. Além disso, como o estudo visa identificar as dificuldades e possíveis soluções, tem-se a expectativa de aprimorar a elaboração das 
monografias no âmbito do curso, o que poderá repercutir na maior qualidade das pesquisas. É relevante a informação de que o questionamento aqui proposto já foi levantado em outras áreas do conhecimento como na Administração (Merg, 2012) e na Enfermagem (Freitas, 2012).

O presente estudo segue com a fundamentação teórica, abordando a formação acadêmica aliada à pesquisa. Posteriormente, são apresentados os procedimentos metodológicos utilizados para o desenvolvimento do estudo. Na quarta parte, tem-se a apresentação e análise dos dados, finalizando com as considerações finais e referências.

\section{Formação acadêmica e trabalho monográfico}

A fim de acompanhar o desenvolvimento da profissão de Secretariado Executivo e responder às exigências de qualificação profissional do mercado de trabalho, foi criado o curso de Secretariado Executivo em nível superior (Bianchi, Alvarenga \& Bianchi, 2003). No Brasil, o primeiro curso na área foi criado em 1969, em Salvador, na Universidade Federal da Bahia [UFBA]. Na década de 1990, ocorreu a expansão dos cursos de graduação em Secretariado em nível nacional, o que fez com que cursos da área se tornassem presentes nas diversas instituições de ensino superior, públicas e privadas, em todas as regiões brasileiras. Aliada à expansão da formação, ocorreu o reconhecimento do profissional no mercado de trabalho, com a regulamentação da profissão e perfil desenvolvido para atender às altas demandas empresariais (Cielo, Schmidt \& Wenningkamp, 2014).

A graduação em Secretariado Executivo atualmente é regida pelas DCN, Resolução no 3, instituída em 23 de junho de 2005. Essa resolução veio atender as novas exigências da Lei de Diretrizes e Bases da Educação [LDB], de 1996, em que o currículo passa a ser mais flexível, bem como evita grande diversidade de conteúdo que possa interferir negativamente em possíveis transferências de estudantes de uma instituição para outra e na continuidade dos estudos (Souza, 1997).

O curso de bacharel em Secretariado Executivo deve atender ao que determina as suas DCN, sendo constituído por disciplinas de diversas áreas do conhecimento de modo a formar um profissional multidisciplinar, preparado para enfrentar as variáveis do mercado. São exigidos: 1) conteúdos básicos relacionados com as ciências sociais, jurídicas, econômicas e da comunicação e informação; 2) conteúdos específicos de secretariado, incluindo as técnicas de trabalho e ética, bem como de administração, psicologia, língua portuguesa e estrangeira; e 3) 
conteúdos teórico-práticos como estágio supervisionado e atividades complementares (Brasil, 2005).

Um fato que interessa a esta pesquisa é que as DCN facultam a produção da monografia para a integralização curricular, deixando a cargo de cada instituição de ensino a decisão de contemplar ou não na estrutura curricular, como já referido na introdução desse texto. Por outro lado, a realização do trabalho monográfico é uma das formas de desenvolver pesquisa científica durante a graduação.

Severino (2007, p. 202), ao discorrer sobre o TCC (que pode ser desenvolvido em formato de monografia), relata que "para grande maioria, ele representa a primeira experiência de realização de uma pesquisa. Como vivência de produção de conhecimento, contribui significativamente para uma boa aprendizagem" e dentre os objetivos da monografia está o de contribuir para o desenvolvimento científico da área. Severino (2007, p. 26) também explica que "executar esses trabalhos é praticar a pesquisa, iniciar-se à vida científica e vivenciar a forma privilegiada de aprender".

Oliveira (1999, p. 236) define monografia como "abordagem de um único assunto, ou problema, sob tratamento metodológico de investigação". E traz como característica essencial "a forma de estudo de um tema (unicidade) delimitado, uma atualidade e originalidade acompanhada de uma contribuição importante para a ampliação do conhecimento específico" (Oliveira, 1999, p. 236).

A monografia não é o único formato de TCC. Outras modalidades são contempladas nas DCN e são consideradas por instituições e cursos como obrigatórias para a conclusão deles, tais como: produção de artigos científicos, papers, relatórios de estágios e projetos de iniciação científica. Além disso, o termo monografia é empregado para manuscritos tanto na graduação quanto na pós-graduação, sendo a dissertação (para mestrado) e a tese (para doutorado) tipos de monografias, diferenciando-se pela profundidade em que o assunto é abordado.

Em levantamento realizado por Oliveira e Durante (2016) sobre a presença de disciplinas ligadas à pesquisa nos cursos de secretariado no país, foi identificada a diversidade das atividades de pesquisa estabelecidas como obrigatórias na integralização curricular desses cursos, confirmando a presença de outras modalidades. O referido estudo abrangeu 56 cursos bacharelados e destes a obrigatoriedade do TCC ou da monografia foi identificada em 25, ou seja, quase $50 \%$, sendo considerado um número positivo pelas autoras e que demonstra que, 
mesmo não sendo obrigatória pelas DCN, vem sendo contemplada nas estruturas curriculares dada a importância para a formação do estudante.

Desse modo, entende-se que a produção monográfica, ao término de uma graduação, confere ao estudante o atingimento de certo grau de maturidade. "A monografia, no contexto da formação acadêmica, representa o ápice de uma pirâmide em cuja base estão o método e as práticas de estudos eficazes" (Lima, 2008, p. 11). Em outras palavras, a produção do trabalho monográfico, na graduação, remete à transição do aluno reprodutor para aquele que de fato produz e pesquisa, interferindo positivamente na formação acadêmica. Ao considerarmos que a monografia é facultativa no curso de bacharelado em Secretariado Executivo, isso pode resultar em deficiência à formação acadêmica dos estudantes.

Demo (2011) igualmente defende que o ensino deve ocorrer através da pesquisa para quebrar o paradigma de ensino como repasse de conhecimento. Para Oliveira e Durante (2016, p. 71), "a exigência do trabalho monográfico é uma forma, não única, de o aluno envolver-se efetivamente com pesquisa durante a graduação e aprofundar conteúdos específicos de Secretariado". A realização da monografia, além de contribuir com a formação acadêmica do estudante, também contribui com o incremento da pesquisa na área.

Tendo as IES a função de produzir conhecimento, não há como questionar a importância da pesquisa no interior dos cursos. As Instituições de Ensino Superior além de incentivarem seus alunos à prática da pesquisa, precisam também apresentar os resultados das pesquisas à sociedade de forma a agregar valor a todo o universo onde o homem se insere (Marques, 2006).

Em se tratando de dificuldades dos estudantes de graduação para a realização de pesquisas, Merg (2012) levantou a falta de tempo do orientador para orientações e limitação de literatura sobre o tema, mas, mesmo assim, a conclusão da monografia significou para os alunos o atingimento de maturidade, conquista e realização. Já no levantamento de Freitas (2012) a principal dificuldade apontada pelos estudantes foi a aplicação das normas técnicas.

Diante do registrado, fica evidente a necessidade da produção monográfica para a introdução do aluno de graduação no universo da pesquisa elevando-o a gerador de conhecimento, bem como para o cumprimento da função da universidade de produzir saberes e gerar resultados para a sociedade. A monografia pode tornar-se um marco na vida do aluno. É o momento em que ele deixa de ser um reprodutor do conhecimento e passa a contribuir como produtor de conhecimento. 


\section{Metodologia}

Este estudo possui abordagem qualitativa visto que buscou compreender o significado e as dificuldades no processo da produção monográfica. A pesquisa qualitativa se caracteriza pela "relação dinâmica entre o mundo real e o sujeito, isto é, um vínculo indissociável entre o mundo objetivo e a subjetividade do sujeito que não pode ser traduzido em números" (Prodanovi \& Freitas, 2013, p. 70). Também tem natureza descritiva, uma vez que se propôs a descrever as percepções e sentimentos dos sujeitos quanto à realização do trabalho monográfico (Gil, 2002).

Em relação ao método, inicialmente foi realizada a revisão da literatura. Nessa fase, buscaram-se estudos da área da Educação que discutem a importância da pesquisa na formação acadêmica, assim como estudos da área secretarial que tratam especialmente da pesquisa em Secretariado. Num segundo momento, foi realizado um levantamento de dados, que, enquanto método, estuda fenômenos que ocorrem naturalmente em uma determinada população e a coleta é realizada diretamente com os sujeitos. De acordo com Gil (2002), essa técnica mostra-se bastante útil para a análise de opiniões e atitudes, contribuindo, portanto, com o objetivo desta pesquisa ao buscar resultados qualitativos através das descrições das opiniões e sentimentos dos sujeitos.

Quanto aos sujeitos da pesquisa, tem-se que compreende os egressos do curso de Secretariado Executivo da UFC, porque esse público já cumpriu o requisito da elaboração e aprovação da monografia, o que permite a eles informar suas percepções acerca do processo. Até o momento desta pesquisa, o curso possuía 541 egressos. Diante da impossibilidade de estudar toda a população, reduziu-se a análise a um grupo. Prodanovi e Freitas (2013, p. 97) afirmam que "de modo geral, as pesquisas sociais abrangem um universo de elementos tão grande que se torna impossível considerá-lo em sua totalidade. Por essa razão, nas pesquisas sociais, é muito frequente trabalhar com uma amostra". Sabendo disso, optou-se por delimitar a pesquisa aos egressos que concluíram o curso no período 2013.2 a 2016.1 , no total de 56 sujeitos. Sendo eles recém-formados e por terem produzido a monografia recentemente, pressupõe-se que ainda possuem em mente as representações e dificuldades que o processo gerou.

A coleta de dados ocorreu por meio de um questionário. Para a elaboração do questionário, inicialmente fez-se um quadro de congruência com os objetivos da pesquisa, 
fundamento teórico e possíveis perguntas que levariam ao alcance dos objetivos. Após análise, cruzamento das informações e pré-teste, o questionário ficou constituído de nove perguntas abertas, direcionadas à experiência vivida pelos sujeitos durante a produção monográfica. $\mathrm{Na}$ coordenação do curso foram obtidas as atas de colação de grau dos semestres 2013.2 a 2016.1 a fim de identificar os sujeitos da pesquisa e seus contatos eletrônicos.

A coleta iniciou no dia 02 de novembro de 2016 com o envio por e-mail do convite para participar do estudo e o questionário anexado. Os sujeitos também foram procurados nas redes sociais a fim de reforçar a importância da participação na pesquisa. O aplicativo Outlook express, que é um gerenciador de e-mails, foi utilizado para ter certeza de que o e-mail foi recebido pelo destinatário. Deste modo, é possível afirmar que os 56 sujeitos da pesquisa receberam o questionário e o convite.

O acompanhamento das respostas foi realizado diariamente após o envio e foi reenviado o arquivo para aqueles que não retornaram com as respostas dentro do prazo estipulado. Ao completar 15 dias estabelecidos para a coleta, obteve-se o retorno satisfatório de 28 sujeitos, do total de 56, ou seja, $50 \%$ do grupo selecionado, o que foi considerado satisfatório por se tratar de estudo qualitativo. Os sujeitos são denominados no texto como Sujeito 1 ao Sujeito 28, para garantir o anonimato dos mesmos.

Para análise de dados, optou-se pela técnica de análise de conteúdo. Para Bardin (2006, p. 38), a análise de conteúdo consiste em "um conjunto de técnicas de análise das comunicações, que utiliza procedimentos sistemáticos e objetivos de descrição do conteúdo das mensagens". Bardin (2006) organiza o processo de análise de conteúdo em três fases, que foram seguidas nesta pesquisa: 1) pré-análise, 2) exploração do material e 3) tratamento dos resultados, inferência e interpretação. Na primeira fase se organizou o material de acordo com os objetivos da pesquisa e a partir de uma leitura prévia para se ter uma visão geral das informações obtidas e a recorrência. A exploração do material ocorreu mediante a codificação, classificação e categorização do material de acordo com o conteúdo das informações obtidas, bem como a contagem de frequência. Na terceira fase os resultados foram tratados. Fez-se a condensação das informações para análise, que culminou com interpretações inferenciais, a partir da análise reflexiva e crítica dos autores. Os resultados e análises são apresentados de forma descritiva, na próxima seção. 


\section{Análise e discussão dos resultados}

Os 28 sujeitos que responderam ao questionário afirmaram ter apresentado suas monografias no curso de Secretariado Executivo da UFC, no período de 2013.2 à 2016.1, atendendo ao critério estabelecido para a definição dos participantes da pesquisa. A título de organização das opiniões dos sujeitos, os dados são apresentados conforme os objetivos específicos do estudo: a) significados atribuídos, b) dificuldades vivenciadas, c) sugestões para diminuição das dificuldades durante a produção monográfica.

\subsection{Significados da produção monográfica}

Questionados sobre o significado de elaborar e defender monografia no curso de Secretariado Executivo da UFC, todos os sujeitos demonstraram opinião positiva e de satisfação. Os significados mais identificados foram de "Desenvolvimento e realização pessoal" e de "Aquisição de mais conhecimento científico e experiência em pesquisa". A esse respeito, Oliveira e Durante (2016, p. 78) já destacaram que dentre os objetivos da monografia está o de desenvolver hábitos de pesquisa que irão interferir tanto na formação acadêmica como no desenvolvimento pessoal e profissional dos envolvidos.

O desenvolvimento e a realização pessoal correspondem a todo o processo de aprendizagem estruturado pela universidade onde o estudante é levado a ampliar sua pessoa, como indivíduo participante da sociedade, e suas habilidades profissionais no meio acadêmico e/ou organizacional. Atribuir como significado da produção monográfica o desenvolver-se pessoalmente também atinge um dos objetivos propostos pelo curso em seu Projeto Pedagógico (UFC, 2006). A fala de um sujeito ilustra sua realização pessoal: "Foi difícil, mas prazeroso ao mesmo tempo. É muito bom, você observar que seu esforço e dedicação deram um resultado positivo. Foi bastante significante e importante pra [sic] mim" (SUJEITO 5).

Quanto à aquisição de conhecimento científico e experiência em pesquisa, são ganhos que estão vinculados à elaboração da monografia, sendo considerada uma das formas de iniciar no universo da pesquisa científica. Ao reconhecer como significados essas aquisições, reafirmase o que foi ressaltado por Severino (2007) que elaborar um trabalho monográfico é praticar e inserir-se no campo da pesquisa científica, ou seja, contribui diretamente na aquisição de conhecimentos específicos da área pesquisada. O Sujeito 4 relatou: "Significou aprendizado 
quanto a se organizar para manusear diversas informações, além de aprender a buscar informações e defender o ponto de vista. Como também aumentar a capacidade crítica". Já para o sujeito 15: "Foi a melhor experiência acadêmica que tive. A monografia contribui para uma visão mais ampla acerca do trabalho científico, e da importância deste para o curso de graduação". Essas opiniões retratam o sentimento de ganho de conhecimento através da experiência vivida com a produção intelectual.

Além desses significados, também foi identificado o significado de gratidão em alguns sujeitos, por poderem contribuir com o desenvolvimento do curso através de pesquisas, gerando conhecimento para a área secretarial na busca de seu fortalecimento. Oliveira e Durante (2016) reconhecem esse sentimento de contribuição do aluno produtor da monografia para com o ensino quando afirmam que "Através da pesquisa científica o aluno passa a produzir conhecimento para a academia e a sociedade" (Oliveira \& Durante, 2016, p. 78).

Outros sujeitos atribuíram como significado o sentimento de dever cumprido. Sobre isso, acredita-se que se trata de uma sensação comum em cada aluno que consegue concluir seu trabalho de forma satisfatória, elevando-o ao grau de graduado. Esse sentimento confirma o escrito por Lima (2008) quando faz referência a produção da monografia como um marco na vida do estudante por ser responsável a gerar conhecimento. Nesse sentido, reproduzimos que um dos participantes demonstrou satisfação pela contribuição ao local de trabalho: "é gratificante poder contribuir com minha pesquisa para o desenvolvimento no meu próprio ambiente de trabalho" (SUJEITO 21).

Visando sintetizar os significados atribuídos à monografia, a tabela 1 apresenta os seis significados em que foi possível agrupar todas as respostas obtidas.

Tabela 1 - Significados atribuídos ao processo de elaboração da monografia

\begin{tabular}{lc}
\hline Significado & Frequência \\
\hline Desenvolvimento e realização pessoal & 10 \\
\hline Aquisição de mais conhecimento científico e experiência em pesquisa & 8 \\
\hline Satisfação de contribuir com o curso/área & 4 \\
\hline Dever cumprido & 3 \\
\hline Trabalho de muita importância & 2 \\
\hline Satisfação em contribuir com o local de trabalho & 1 \\
\hline TOTAL & 28 \\
\hline
\end{tabular}

Fonte: Dados da pesquisa (2016). 
De modo complementar, os sujeitos foram indagados sobre como definem a produção da monografia para o desenvolvimento do secretariado executivo enquanto profissão. Os sujeitos destacaram contribuições para a evolução da profissão e do profissional secretário executivo, ratificando os significados anteriormente descritos. Os três trechos que seguem exemplificam os achados:

Seja em qualquer área, a pesquisa tem um papel imprescindível. É através da pesquisa que uma profissão ou área do conhecimento evolui. No Secretariado principalmente, visto que é uma área que ainda busca se consolidar cientificamente, apesar da sua inquestionável ascensão no âmbito profissional. $\mathrm{O}$ acadêmico que faz monografia, sem dúvida, torna-se um profissional mais qualificado, com visão crítica e habilidades analíticas mais apuradas, o que contribuirá significativamente para o desenvolvimento do seu trabalho enquanto assessor, gestor, empreendedor ou consultor (SUJEITO 01).

Crescimento profissional através do conhecimento científico (SUJEITO 02).

Mais produção bibliográfica na área, mais intimidade com a profissão, é possível ver realidade da profissão e profissionais de perto (SUJEITO 19).

As respostas compactuam com os significados atribuídos à produção monográfica, sentimento de satisfação por contribuir com a área, com local de trabalho e com o desenvolvimento profissional. Todas as respostas obtidas foram reunidas pela similaridade dos conteúdos expressos e são apresentadas na Tabela 2.

Tabela 2 - Significado da produção da monografia para o desenvolvimento do secretariado executivo enquanto profissão.

\begin{tabular}{lc}
\hline Significado & Frequência \\
\hline Importância da pesquisa para o desenvolvimento da profissão & 7 \\
\hline Valoriza e fortalece o acadêmico e o profissional & 7 \\
\hline Profissionais mais qualificados, com visão crítica e habilidades apuradas & 5 \\
\hline Reconhecimento acadêmico & 4 \\
\hline Importante por abordar a realidade e atualizar conceitos & 4 \\
\hline Evolução acadêmica nos níveis lato sensu e stricto sensu & 1 \\
\hline TOTAL & 28 \\
\hline
\end{tabular}

Fonte: Dados da pesquisa (2016).

Como pode ser constatado nas tabelas 1 e 2, os sujeitos revelam a importância da monografia para a formação acadêmica e revelam o sentimento de satisfação por terem vivido essa etapa e pelos benefícios que obtiveram no desenvolvimento pessoal e profissional. Tais 
opiniões conferem com os pressupostos teóricos apresentados nesse estudo (Severino, 2007; Lima, 2008; Demo, 2011; Oliveira \& Durante, 2016).

Como a monografia é um componente obrigatório na UFC, buscou-se investigar se a obrigatoriedade tem alguma relação com os significados atribuídos. Os sujeitos foram convidados a opinar sobre a concordância ou discordância da obrigatoriedade e justificar suas respostas. Quanto a obrigatoriedade, 19 dos 28 sujeitos concordaram, justificando a importância de o aluno criar conhecimentos científicos e consolidar seu aprendizado no final do curso. Enquanto oito sujeitos discordaram da obrigatoriedade justificando que a atividade poderia ser optativa sob alegação de que a produção científica deve partir da iniciativa própria do aluno. Um participante não opinou.

Os sujeitos também foram questionados se a produção da monografia incentivou a realização de novas pesquisas ou a continuidade dos estudos acadêmicos em cursos lato ou stricto sensu. A esse respeito, 18 afirmaram que se sentiram incentivados depois de produzir a monografia. Durante e Santos (2012), entre outros, já apontaram que o envolvimento do aluno com a pesquisa durante a graduação estimula-o a continuar seus estudos em nível de pósgraduação. Por outro lado, 10 sujeitos registraram que não se sentiram incentivados, justificando a falta de tempo, não ter gostado da experiência de produzir a monografia ou por não ter interesse em seguir na profissão.

Para finalizar essa parte, foi questionado se o estudante de secretariado executivo deve ser capacitado para a pesquisa científica. Os sujeitos participantes foram unanimes nas respostas, relatando como motivos a importância para a difusão e fortalecimento da área e para o desenvolvimento de habilidades profissionais e pessoais. Desse modo, apesar de alguns sujeitos não concordarem com a obrigatoriedade e não se sentirem motivados a realizar futuras pesquisas e continuar seus estudos, mesmo assim, evidenciam a importância de o profissional secretário executivo ser capacitado para a pesquisa. Com isso, cumpre-se o primeiro objetivo da pesquisa que é compreender o significado da produção monográfica na visão dos alunos.

\subsection{Dificuldades vivenciadas durante a produção monográfica}

Outro objetivo desta pesquisa foi levantar as dificuldades encontradas pelos estudantes na elaboração da monografia. Os sujeitos foram questionados acerca de possíveis dificuldades relacionadas com: a) o tempo e prazos; b) o processo de orientação; c) a estrutura da biblioteca; 
d) os seus conhecimentos prévios; e) a sua habilidade de escrita; e f) a literatura direcionada ao tema proposto. A tabela 3 apresenta a frequência das respostas.

Tabela 3 - Dificuldades vivenciadas durante a produção da monografia

\begin{tabular}{|c|c|c|c|c|c|c|}
\hline & Tempo/prazo & Orientação & Biblioteca & $\begin{array}{c}\text { Conhecimento } \\
\text { prévio }\end{array}$ & Escrita & $\begin{array}{c}\text { Literatura } \\
\text { direcionada } \\
\text { ao tema }\end{array}$ \\
\hline $\begin{array}{l}\text { Não teve } \\
\text { dificuldade }\end{array}$ & 10 & 19 & 12 & 18 & 17 & 14 \\
\hline $\begin{array}{c}\text { Teve } \\
\text { dificuldade }\end{array}$ & 18 & 9 & 16 & 9 & 9 & 12 \\
\hline $\begin{array}{c}\text { Não } \\
\text { respondeu }\end{array}$ & - & - & - & 1 & 2 & 2 \\
\hline TOTAL & 28 & 28 & 28 & 28 & 28 & 28 \\
\hline
\end{tabular}

Fonte: Dados da pesquisa (2016).

A falta de tempo para cumprir os prazos foi a dificuldade mais apontada. A maioria afirmou que teve dificuldades para conciliar a produção científica com o estudo de outras disciplinas, além do trabalho, família e imprevistos. Também foram citados como empecilhos: o curto prazo; a falta de hábito em pesquisa; e não ter o tema definido com antecedência. A falta de tempo já foi citada por Durante e Pereira (2016) como um dos motivos dos alunos não se inserirem em atividades de pesquisa e atividades extraclasse de modo geral. Os sujeitos que afirmaram não ter ocorrido dificuldades justificaram que o tempo e o prazo são suficientes para a produção do trabalho, tendo como fator importante uma eficiente organização e determinação. É relevante lembrar que na estrutura curricular do curso de Secretariado Executivo da UFC a monografia está prevista no oitavo semestre, juntamente com uma disciplina obrigatória e outras optativas. Além disso, é comum o estudante chegar neste estágio de finalização do curso com disciplinas pendentes de semestres anteriores, o que acarreta em menor tempo para se dedicar ao trabalho monográfico.

Em relação ao processo de orientação, a maioria respondeu que não teve dificuldades e que obteve ótimo relacionamento com o orientador (a), considerando o acompanhamento satisfatório e essencial para a realização do trabalho. A minoria que ficou insatisfeita com a orientação relatou problemas com a disponibilidade do orientador (a) e contratempos no alinhamento do tema proposto com a área de estudos do docente.

Quanto à estrutura da biblioteca, as opiniões são equilibradas; parte dos sujeitos informou não terem encontrado dificuldades, pois ela possui boa estrutura e de fácil acesso, 
enquanto para outros, a biblioteca oferece pequeno acervo dificultando a pesquisa, tendo muitas vezes que recorrer à compra de livros para suprir essas necessidades. Ao falar sobre a literatura, os sujeitos também se mantiveram parciais, pois 14 responderam que não tiveram dificuldades, destacando que os temas escolhidos possuíam literatura vasta e atualizada. Já os outros 12 sentiram dificuldades quanto à literatura na área secretarial que abrangesse o tema em estudo.

No que diz respeito às dificuldades oriundas dos conhecimentos prévios e da habilidade de escrita, a maioria respondeu que não tiveram problemas quanto a essas abordagens e afirmaram que as disciplinas de estágio e Metodologia do trabalho científico, também constantes na estrutura curricular, foram importantes na produção do trabalho pois nelas obtiveram contato com a metodologia e estrutura a serem desenvolvidas durante a monografia. Também foi relatado que a cobrança da leitura e produção de artigos durante o curso ajudou bastante nesses quesitos. Os outros sujeitos que sentiram dificuldades nesses contextos citaram o pouco conhecimento sobre a metodologia, o pouco conhecimento em produção científica, a falta de leitura e a falta de habilidade com as orientações da Associação Brasileira de Normas e Técnicas [ABNT], como os fatores responsáveis.

As dificuldades que ocorrem durante o processo da monografia geralmente estão relacionadas com os alunos que não possuem o hábito de ler e de produzirem trabalhos científicos. Dados do Exame Nacional de Desempenho dos Estudantes [ENADE] 2012 revelam que a leitura não é um hábito comum entre os alunos de secretariado. Os registros mostram que apenas 13,2\% leram mais de 8 livros por ano, 7,5\% não realizou nenhuma leitura, 33,8\% leram um ou dois livros 34,5\% leram entre três ou cinco livros e 11,1\% leram entre 6 e 8 livros (Inep, 2012). Possuir esses hábitos torna a produção da pesquisa mais ágil e eficaz, visto que o aluno terá experiência quanto a estrutura e métodos e conhecimento antecipado sobre o tema que irá pesquisar.

Com isso, conclui-se que, em parte, as dificuldades podem ser minimizadas pelo curso e IES e, em parte, são de responsabilidade dos próprios estudantes quando não se habituam a produzir trabalhos científicos durante a vida acadêmica, bem como não praticam a leitura com assiduidade. Em relação a leitura, há de se levar em consideração a queixa registrada pelos sujeitos da pouca literatura secretarial constante na biblioteca, porém é algo que pode ser compensado através de materiais em periódicos e anais de eventos que são de acesso público. 


\subsection{Sugestões para as dificuldades, na visão dos ex-alunos}

Ao serem indagados sobre sugestões para os problemas relatados anteriormente, os sujeitos citaram fatores a serem tratados em âmbito pessoal e âmbito institucional, conforme segue.

Quadro 1 - Sugestões

\begin{tabular}{|l|l|}
\hline Sugestões & $\begin{array}{l}\text { O aluno possuir disciplina e organização para realizar o trabalho no tempo estabelecido } \\
\text { e ter maior compromisso com a produção. }\end{array}$ \\
\cline { 2 - 2 } ASPECTOS & O aluno buscar conhecer, previamente, o tema que deseja pesquisar. \\
\cline { 2 - 2 } PESSOAIS & O aluno elaborar o projeto de pesquisa com antecedência. \\
\hline \multirow{4}{*}{$\begin{array}{l}\text { OSPECTOS aumento de produção científica na área secretarial } \\
\text { INSTITUCIONAIS }\end{array}$} & $\begin{array}{l}\text { A IES oferecer maior acervo bibliográfico específico em secretariado e afins } \\
\text { início do curso através da inclusão de outras disciplinas de Metodologia, Projeto de } \\
\text { pesquisa e Monografia }\end{array}$ \\
\cline { 2 - 2 } & $\begin{array}{l}\text { O curso ser estruturado de forma que o aluno tenha apenas a monografia como } \\
\text { obrigatória no último semestre }\end{array}$ \\
\cline { 2 - 2 } & Os professores orientadores terem maior comprometimento com o aluno. \\
\hline
\end{tabular}

Fonte: Dados da pesquisa (2016).

Dentre as sugestões apresentadas estão o aluno possuir organização e determinação quanto às características necessárias para a produção monográfica, sendo ele responsável pelo estabelecimento do tema que desejará pesquisar e pelo seu nível de conhecimento sobre o assunto. Um fator que é considerado importante para o desenvolvimento dessas habilidades para a produção científica é a inserção em grupos de pesquisas ou grupos de estudos, participação em eventos acadêmicos, entre outros (Durante \& Pereira, 2016; Sanches, Schmidt, Cielo \& Wenningkamp, 2016).

Já no que concerne aos aspectos institucionais, identifica-se a necessidade de aumentar a produção científica na área, sendo que a obrigatoriedade da monografia nos cursos bacharelados em Secretariado Executivo poderia favorecer a isso. Também, é necessário que a UFC reveja a situação de disponibilidade de seu acervo bibliográfico a fim de uma atualização e aumento da quantidade de exemplares. Outro fator destacado foi a reestruturação curricular do curso, incluindo mais disciplinas voltadas para o desenvolvimento de habilidades de pesquisa, a ampliação do tempo para a realização da monografia e maior atenção dos orientadores aos alunos. 
As soluções apontadas são consideradas importantes para melhorias da qualidade da monografia. Estar atento aos fatores citados é uma forma de o aluno não passar pelos mesmos problemas relatados pelos egressos ou se preparar antecipadamente. As demandas institucionais são fatores que não dependem diretamente do aluno, mas, quando conhecidas pelos alunos, possibilitam que esses busquem estratégias antecipadamente para evitar os mesmos percalços.

\section{Considerações finais}

Compreender o significado atribuído à elaboração do trabalho monográfico, na visão dos ex-alunos do curso bacharelado em Secretariado Executivo da Universidade Federal do Ceará, no período de 2013.2 a 2016.1, foi o propósito deste estudo.

Na revisão teórica ficou evidenciado que a pesquisa científica se faz importante para todas as áreas do conhecimento e que a realização da monografia é um dos meios do estudante se inserir no universo da pesquisa durante a graduação. Para a área de secretariado, a monografia representa fortalecimento acadêmico e profissional e, mesmo sendo opcional em suas DCN, mostra-se necessária para o fortalecimento da formação e reconhecimento perante a sociedade.

Com o levantamento de dados junto os ex-alunos se evidenciou a importância da produção da monografia para os estudantes e para o ensino superior, bem como para toda a área secretarial, seja ela acadêmica ou profissional. Ao se obter como significado da monografia o desenvolvimento, a realização pessoal, a aquisição de conhecimento científico e a experiência em pesquisa, isso reflete a situação em que o estudante, além de adquirir habilidades na produção científica, concomitantemente, contribui com o enriquecimento da área.

Realizar a monografia como a última atividade solicitada pela graduação tem sua contribuição no desenvolvimento pessoal e profissional e, mesmo que alguns respondentes tenham discordado da obrigatoriedade dessa atividade, foram unânimes em defender que os estudantes do secretariado devem ser capacitados para a pesquisa.

Outro fator que merece destaque é que a experiência com a produção da monografia gera incentivo na realização de novas pesquisas ou continuidade dos estudos. $\mathrm{O}$ fato dessa produção despertar tal desejo reforça sua importância pois, desta forma, atende-se a expectativa de formar pesquisadores em secretariado, fortalecer a pesquisa e aumentar o conhecimento científico. 
Os resultados mostraram-se satisfatórios, representando o cumprimento dos objetivos da universidade quanto à indissociabilidade entre ensino e pesquisa, sendo a monografia uma possibilidade de os alunos desenvolverem pensamento crítico, gerarem conhecimentos e serem sujeitos ativos na formação. Foram detectadas também dificuldades durante o processo de realização da monografia, dificuldades em âmbito pessoal, que dependem do próprio aluno, e dificuldades em âmbito institucional, que dependem de ações do curso e da IES, mas todas mostraram-se possíveis de serem solucionadas. As dificuldades apontadas parecem não comprometerem a realização do trabalho monográfico.

A realização de pesquisa científica durante a graduação, seja em formato de TCC, monografia ou artigo científico, é considerada positiva pois é uma forma de introduzir o aluno no universo da pesquisa e exige estudo autônomo, o exercício do questionamento, da reflexão e da criação de conhecimentos. Ou seja, é uma forma de o estudante interagir ativamente com o conhecimento científico. Além disso, no Secretariado Executivo, a pesquisa durante a graduação é essencial visto que a área não possui tradição em pesquisa e precisa construir uma cultura em torno dela.

Entender os significados, as dificuldades e as soluções na produção da monografia sob a visão dos ex-alunos, cooperam com o conhecimento sobre o comportamento do estudante diante do seu desenvolvimento durante a graduação e suas expectativas quanto a sua inserção no meio científico, através da continuidade na produção científica e/ou em cursos de extensão. Por isso, a realização deste estudo cumpriu com seu objetivo. Esta pesquisa possibilita apontar que esse é o momento da instituição, em conjunto com os docentes e discentes do curso, buscar incrementar o incentivo nas produções científicas, atendendo as soluções indicadas, no intuito de aumentar a literatura secretarial, fortalecendo ao curso e a área.

A importância de o aluno envolver-se com a investigação científica durante a graduação, somada aos significados atribuídos por estudantes que já vivenciaram esse processo, significados de satisfação e desenvolvimento pessoal e profissional, sugerem que a realização da atividade monográfica é benéfica, pois através de sua execução adquire-se a criticidade, além de outras características pertinentes a ela.

Diante desse fato, propõe-se a revisão das DCN de modo que a atividade de monografia se torne obrigatória em todos os cursos de secretariado do Brasil. Reconhecem-se as limitações desta pesquisa, por se restringir a um grupo de egressos de um curso do país. Por isso, a continuidade do estudo em outros cursos que também possuem a atividade de monografia 
como obrigatória é essencial ao desenvolvimento da área e que outros atores, por exemplo, os professores, sejam ouvidos.

\section{Referências}

Associação Brasileira de Pesquisa em Secretariado. (2016). A pesquisa em Secretariado. $\begin{array}{lllll}\text { Recuperado } & \text { em } & 02 & \text { novembro, }\end{array}$ $<$ http://www.abpsec.com.br/abpsec/index.php/a-pesquisa-em-secretariado>.

Associação Brasileira de Pesquisa em Secretariado. (2016). Histórico de notícias. Recuperado em 02 novembro, 2016, de <http://www.abpsec.com.br/abpsec/index.php/noticias/11013-10-2014-novo-grupo-de-secretariado-cadastrado-no-cnpq>.

Bardin, L. (2006). Análise de conteúdo. Lisboa: Edições 70.

Bianchi, A. C. de M, Alvarenga, M., \& Bianchi, R. (2003). Orientação para estágio em secretariado: trabalhos, projetos e monografias. São Paulo: Pioneira Thomson Learning.

Brasil. (2005). Resolução $n^{o}$ 3, de 23 de junho de 2005. Recuperado em 07 setembro, 2016, de $<$ http://portal.mec.gov.br/cne/arquivos/pdf/rces003_05.pdf $>$.

Cantarotti, A. (2016). Formação, mercado de trabalho e pesquisa científica em secretariado: por onde começamos? In: Durante, D. G., Martins, C. B., \& Cantarotti, A. (Org.). Pesquisa em secretariado: Reflexões acerca da Construção do Conhecimento. Fortaleza: Edições UFC.

Cielo, I. D., Schmidt, C. M., \& Wenningkamp, K. R. (2014). Secretariado Executivo no Brasil: quo vadis? R. G. Secr., GESEC., 5(3), 49-70. Recuperado em 08 outubro, 2016, de $<$ http://www.spell.org.br/documentos/ver/38944/secretariado-executivo-no-brasil-quo-vadis-/i/pt-br>

Demo, P. (2011). Educar pela pesquisa. (8a ed.). Campinas: Editora Autores Associados.

Durante, D. G. (2012). A evolução da profissão por meio da pesquisa. In: Durante, D. G., \& Favero, A. (Org.). Pesquisa em Secretariado: cenários, perspectivas e desafios. Passo Fundo: UPF Editora.

Durante, D. G., \& Pereira, W. C. R. (2016). Pesquisa em secretariado: influência da disciplina de metodologia do trabalho científico. Revista Capital Científico Eletrônica, 14(1). $\begin{array}{lllll}\text { Recuperado } & \text { em } & 15 & \text { outubro, }\end{array}$ 
$<$ http://www.spell.org.br/documentos/ver/41765/pesquisa-em-secretariado--influenciada-disciplina-de-metodologia-do-trabalho-cientifico-/i/pt-br>.

Durante, D. G., \& Santos, M. E. M. (2012). Contribuições da iniciação científica na formação do secretário executivo: vivências no Geseb. In: Durante, D. G., \& Favero, A. (Orgs.). Pesquisa em Secretariado: cenários, perspectivas e desafios. 1ed. Passo Fundo: UPF Editora.

Freitas, T. C. S. (2012). A percepção dos discentes sobre as dificuldades na produção do trabalho acadêmico. In: Seminário de pesquisa em educação da região sul, 9, Caxias do Sul - RS. Anais. Recuperado em 09 setembro, 2016, de $<$ http://www.portalanpedsul.com.br/admin/uploads/2012/Politica_de_Educacao_Super ior/Trabalho/05_17_58_77-7365-1-PB.pdf>.

Gil, A. C. (2002). Como elaborar projetos de pesquisa. (4a ed.). São Paulo: Atlas.

Instituto Nacional de Estudos e pesquisas Educacionais Anísio Teixeira - Inep. (2012). Relatório Síntese 2012. Recuperado em 15 novembro, 2016, de $<$ http://download.inep.gov.br/educacao_superior/enade/relatorio_sintese/2012/2012_re 1_secretariado_executivo.pdf>.

Lima, M. C. (2008). Monografia: a engenharia da produção acadêmica. (2a ed.). São Paulo: Saraiva.

Maçaneiro, M. (2012). A construção da identidade científica em Secretariado Executivo. In: Durante, D. G., \& Favero, A. (Orgs.). Pesquisa em Secretariado: cenários, perspectivas e desafios. Passo Fundo: UPF Editora.

Marques, M. O. (2006). Escrever é preciso: o princípio da pesquisa. (5. ed.). Ijuí: Ed. Unijuí.

Martins, C. B., Maccari, E. A., Silva, A. de O., \& Todorov, M. do C. A. (2014). Retrato dos periódicos científicos de Secretariado no Brasil. Eccos, São Paulo, 2(34), 63-83, maio. DOI: https://doi.org/10.5585/eccos.n34.4631

Merg, C. R. (2012). A elaboração do trabalho de conclusão de curso no curso de Administração da Unijuí: significados, facilidades e dificuldades. 69 p. Trabalho de Conclusão de Curso (Bacharelado em Administração) - Universidade Regional do Noroeste do estado do RS, Panambi, 2012. Recuperado em 28 agosto, 2016, de: $<$ http://bibliodigital.unijui.edu.br:8080/xmlui/bitstream/handle/123456789/1176/TCC $\% 20$ Cristine $\% 20$ vers $\%$ c3\%a3o\%20final\%202012.pdf?sequence $=1>$. 
Oliveira, M. M. (1999). Como fazer projetos, relatórios, monografias, dissertações e teses. (5.ed.). [rev.]. Rio de Janeiro: Elsevier.

Oliveira, N. V., \& Durante, D. G. (2016). Os cursos de secretariado executivo incentivam a pesquisa? In: Durante, D. G., Martins, C. B., \& Cantarotti, A. (Orgs.). Pesquisa em secretariado: Reflexões acerca da Construção do Conhecimento. Fortaleza: Edições UFC.

Piccoli, A. L., Gonçalves, J. F. T., Soares, S. V., \& Martins, C. B. (2016). Secretariado Executivo e a pesquisa acadêmica: uma análise sobre a necessidade da criação de curso stricto sensu. In: Durante, D. G., Martins, C. B., \& Cantarotti, A. (Orgs.). Pesquisa em secretariado: Reflexões acerca da Construção do Conhecimento. Fortaleza: Edições UFC

Prodanovi, C. C., \& Freitas, E. C. (2013). Metodologia do trabalho científico [recurso eletrônico]: métodos e técnicas da pesquisa e do trabalho acadêmico. (2a ed.). Novo Hamburgo: Feevale.

Sanches, F. C., Schmidt, C. M., Cielo, I. D., \& Wenningkamp, K. R. (2016). Grupos de pesquisa em secretariado: uma análise sobre a cooperação científica internacional. In: Durante, D. G.; Martins, C. B., \& Cantarotti, A. (Orgs.). Pesquisa em secretariado: Reflexões acerca da Construção do Conhecimento. Fortaleza: Edições UFC.

Severino, A. J. (2007). Metodologia do trabalho científico. (23a ed.). São Paulo: Cortez.

Souza, P. N. (1997). LDB e ensino superior: (estrutura e funcionamento). São Paulo: Pioneira. Universidade Federal do Ceará - UFC. (2006). Projeto Político-Pedagógico do curso de Secretariado Executivo. Fortaleza, CE. Recuperado em 10 setembro, 2016, de <https://si3.ufc.br/sigaa/public/curso/ppp.jsf?lc=pt_BR\&id=657453>. 